\title{
Tributylphosphine as an Efficient Catalyst in $C$-Vinylation of Naphthol Derivatives
}

\author{
ALIREZA HASSANABADI ${ }^{* a}$, MOHAMMAD H. MOSSLEMIN ${ }^{\mathrm{b}}$ and \\ ZAHRA ALSADAT RASOLHOSSEINI ${ }^{\mathrm{b}}$
}

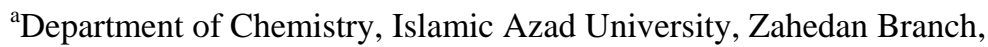
P.O. Box 98135-978, Zahedan, Iran

${ }^{\mathrm{b}}$ Department of Chemistry, Islamic Azad University, Yazd Branch, P.O. Box 89195-155, Yazd, Iran

ar_hasanabadi@yahoo.com

Received 20 May 2012 / Accepted 4 June 2012

\begin{abstract}
A diastereospecific $c$-vinylation of naphthol derivatives is described from a reaction of dialkyl acetylenedicarboxylate and naphthol derivatives, in the presence of tributylphosphine as an efficient catalyst, in excellent yield. The presented one-pot method is simple and effective with mild conditions.
\end{abstract}

Keywords: $C$-Vinylation, Dialkyl acetylenedicarboxylates, Tributylphosphine, Naphthol derivatives

\section{Introduction}

Vinylation of aromatic compounds is an important reaction in organic synthesis and much attention has been paid to the synthesis of vinyl compounds and their functionalized derivatives. However, there are few reports on direct vinylation of aromatic compounds ${ }^{1}$. In 1908, pure $O$-vinyl phenol was synthesized for the first time by decarboxylation of $o$-hydroxycinnamic acid ${ }^{2}$. Since then, a number of methods were devoted to the synthesis of vinylphenols. Electrophilic acylation of phenol followed by reduction and dehydration was employed in the commercial production of $p$-vinylphenol by Maruzen Petrochemicals $\mathrm{Co}^{3}$. Another method that utilized benzylic oxidation of ethylphenol was reported ${ }^{4}$. Halophenol derivatives could be vinylated by the Heck reaction ${ }^{5}$. Pyrolysis of hetrocyclic compounds was reported $^{6}$. The palladium-catalyzed arylation of olefins with aryl halides is a wellestablished method of carbon-carbon bond formation. Because this versatile reaction, discovered by Heck ${ }^{7}$ and Mizoroki ${ }^{8}$, is tolerant of a wide variety of functional groups on either coupling partner, it has gained much interest for the preparation of elaborate arenes from relatively simple starting materials ${ }^{9}$. Ortho-vinylation reaction of anilines was reported in the literature ${ }^{10}$. In recent years there has been increasing interest in the synthesis of organophosphorus compounds, particularly those bearing a carbon atom bound directly to a 
phosphorus atom. This interest has resulted from the recognition of the value of such compounds for a variety of industrial and chemical synthetic uses. Organophosphorus compounds also have been extensively used in organic synthesis as useful reagents as well as ligands of a number of trasition metal catalysts ${ }^{11-17}$. However, there are few reactions in which organophosphorus(III) species work as catalysts ${ }^{17-19}$.

Development of a new approach for a highly stereoselective and efficient $C$-vinylation of naphthol derivatives is still in demand. Previously, in our investigations of stable phosphorus ylides, many condensation reactions between triphenylphosphine and dialkyl acetylenedicarboxylate in the presence of $\mathrm{C}-\mathrm{H}, \mathrm{N}-\mathrm{H}, \mathrm{O}-\mathrm{H}$ or $\mathrm{S}-\mathrm{H}$ acidic organic compounds were reported $^{20-28}$. Herein, we introduce a new method for the diastereospecific synthesis of $(E)$ - $C$-vinyl naphthol derivatives from a reaction between dialkyl acetylenedicarboxylate and naphthol derivatives in the presence of tributylphosphine.

\section{Experimental}

Melting points were determined with an Electrothermal 9100 apparatus. IR spectra were recorded on a Shimadzu IR-470 spectrometer. ${ }^{1} \mathrm{H},{ }^{13} \mathrm{C}$ and spectra were recorded on BRUKER DRX-500 AVANCE spectrometer in $\mathrm{CDCl}_{3}$ using TMS as internal standard. The chemicals used in this work were purchased from Fluka (Buchs, Switzerland) and were used without further purification.

\section{General procedure for preparation of compounds (4a-g)}

To a magnetically stirred solution of naphthol derivative (2 mmol) and tributylphosphine ( $2 \mathrm{mmol}$ ) in $10 \mathrm{~mL}$ acetone, a mixture of dialkyl acetylenedicarboxylate $(2 \mathrm{mmol})$ in $2 \mathrm{~mL}$ acetone was added at $-4{ }^{\circ} \mathrm{C}$ over $5 \mathrm{~min}$. The reaction mixture was then allowed to stir for $12 \mathrm{~h}$. The solvent was evaporated at reduced pressure. The residue was precipitated in a solution of diethyl ether-hexane. The solid was filtered and washed with diethyl ether to give the pure product.

\section{Results and Discussion}

The reaction of dialkyl acetylenedicarboxylate (2) with naphthol derivatives (3), in the presence of tributylphosphine (1) as an efficient catalyst, leds to diastereospecific $C$-vinylation of those in high yields (Figure 1).

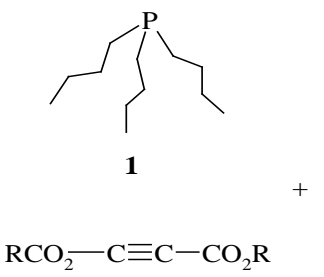

2

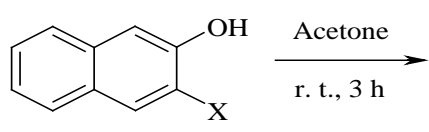

3<smiles>[R]OC(=O)C=C(C=O)c1c(O)c([X])cc2ccccc12</smiles>

E-isomer

4

Figure 1. Synthesis of $C$-vinylation of naphthol derivatives

These reactions were carried out in acetone at $-4{ }^{\circ} \mathrm{C}$. The compounds $\mathbf{4 a - g}$ (Table 1 ) result from the initial addition of tributylphosphine (1) to dialkyl acetylenedicarboxylate (2) and subsequent protonation of the 1:1 adduct by naphthol derivative 3 . Then, the positively charged ion $\mathbf{5}$ is attacked by the anion $\mathbf{6}$ to form ylide 7. Phosphonium ylide undergoes 1,2-H shift to give compound 8. Next, tributylphosphine is going out for generating alkenes 4 . The proposed mechanism for $C$-vinylation of naphthol derivatives is shown in Figure 2. 
Table 1. $C$-Vinylation of naphthol derivatives

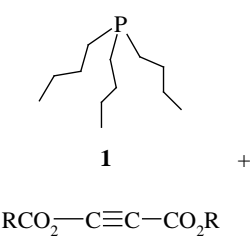

2

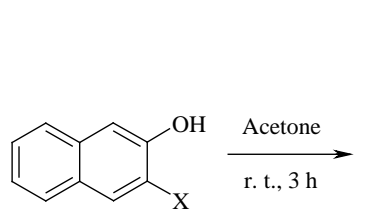

3<smiles>[X]c1cc2ccccc2c(/C(C=O)=C\C(=O)O)c1O</smiles>

4

\begin{tabular}{|c|c|c|c|c|c|c|c|}
\hline \multirow{2}{*}{ Entry } & \multirow{2}{*}{$\mathrm{X}$} & \multirow{2}{*}{$\mathrm{R}$} & \multirow{2}{*}{ Product } & \multirow{2}{*}{ Time/h } & \multirow{2}{*}{ Yield $\%^{\mathrm{a}}$} & \multicolumn{2}{|c|}{ m.p. $/^{\circ} \mathrm{C}$} \\
\hline & & & & & & Found & Reported $^{28,29}$ \\
\hline 1 & & $\mathrm{Me}$ & $4 a$ & 12 & 90 & $179-181$ & 180 \\
\hline 2 & & Et & $4 \mathbf{b}$ & 12 & 84 & $62-64$ & 65 \\
\hline 3 & & $\mathrm{i}-\mathrm{Pr}$ & 4c & 12 & 88 & $84-86$ & 85 \\
\hline 4 & & Me & 4d & 12 & 95 & $178-180$ & $179-181$ \\
\hline 5 & & Et & $4 e$ & 12 & 93 & $166-168$ & $168-170$ \\
\hline 6 & & $\mathrm{Me}$ & $4 f$ & 12 & 92 & $165-167$ & $163-165$ \\
\hline 7 & & Et & $4 g$ & 12 & 90 & $153-155$ & $154-156$ \\
\hline
\end{tabular}

${ }^{a}$ Yield refer to the pure isolated products<smiles>COc1c(N(C)C(=O)[AlH2])cc2ccccc2c1CCC(C(=O)O)=C(C)C(=O)O</smiles>

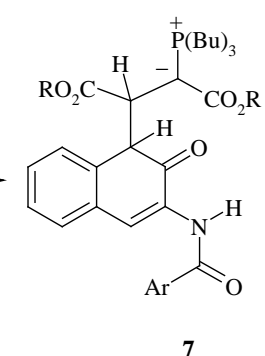

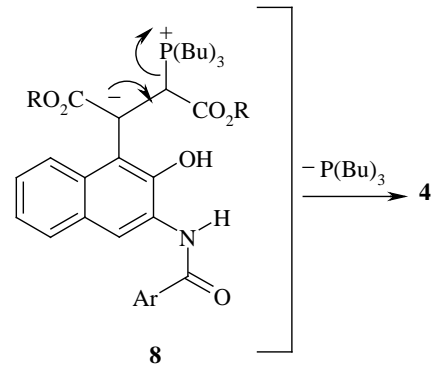

Figure 2. Suggested mechanism for formation of compound 4

The compounds 4a-g were characterised by their ${ }^{1} \mathrm{H},{ }^{13} \mathrm{C}$ NMR and IR spectroscopy and elemental analyses. The structures of the those were proved by comparing the ${ }^{13} \mathrm{C}\left\{{ }^{1} \mathrm{H}\right\} \mathrm{NMR}$ spectral data of related compounds reported elsewhere ${ }^{28,29}$. The chemical shift of the olefinic proton in the ${ }^{1} \mathrm{H}$ NMR spectrum of compounds are consistent with the E-geometry of the carbon-carbon double bond ${ }^{30}$.

\section{Conclusion}

We have shown that tributylphosphine as an efficient catalyst has advantages in the $C$-vinylation of naphthol derivatives such as shorter reaction times, simple work-up and affords excellent yield. The present method carries the advantage that, not only is the reaction performed under neutral conditions, but the educts can be mixed without any activation or modification.

\section{Acknowledgement}

We gratefully acknowledge financial support from the Research Council of Islamic Azad University of Zahedan and The Islamic Azad University of Yazd of Iran. 


\section{References}

1. Kiyoshi Kikukawa, Kiyoshi Kono, Fumio Wada, Tsutomu Matsuda, J Org Chem., 1983, 48, 1333-1336.

2. $\quad$ Fries K and Fickewirch G, Chem Ber., 1908, 41, 367.

3. $\quad$ Everhart E T and Caig J C, J Chem Soc Perkin Trans., 1991, 1, 1701.

4. Emerson W S, Heyd J W, Lucas V E, Cook W B, Owens G R and Shortridge R W, J Am Chem Soc., 1946, 68, 1665.

5. Rollin Y, Meyer G, Troupel M and Fauvarque F J, J Perichon J Chem Soc Chem Commun., 1983, 793.

6. $\quad$ Buchi G and Burgress E M, J Am Chem Soc., 1962, 84, 3104-3109.

7. Heck R F and Nolly J P, J Org Chem., 1972, 37, 2320-2322.

8. Mizoroki T, Mori K and Ozaki A, Bull Chem Soc Jpn., 1971, 44(2), 581.

9. Heck R F, Palladium Reagents Inorganic Synthesis, Academic Press, London, 1985.

10. Masahiko Yamaguchi, Mieko Arisawa, Masahiko Yamaguchi and Masahiro Hirama Chem Commun., 1998, 1399.

11. Cobridge D E C, Phosphorous an Outline of Chemistry, Biochemistry and Uses, $5^{\text {th }}$ Ed., Elsevier, Amesterdam, 1995.

12. Engel R, Synthesis of Carbon-Phosphorous Bond, CRC Press, Boca Raton, FL, 1988.

13. Cadogan J I G, Organophosphorus Reagents in Organic Synthesis, Academic Press, New York, 1979.

14. Kolodiazhnyi O I, Russ Chem Rev., 1997, 66(3), 225-254.

15. Bestmann H J and Vostrowsky O, Top Curr Chem., 1983, 109, 85.

16. Johnson A W, Ylide Chemistry, Academic Press, New York, 1966.

17. Amri H, Rambaud M and Villieras J, Tetrahedron Lett., 1989, 30, 7381.

18. Inanaga J, Baba Y and Hanamoto T, Chem Lett., 1993, 241.

19. Yavari I and Ramazani A, Synth Commun., 1997, 27, 1449-1454.

20. Anary-Abbasinejad M and Hassanabadi A, J Chem Res., 2007, 475.

21. Anary-Abbasinejad M, Mosslemin M H, Hassanabadi A and Tabatabaee M, Synth Commun., 2008, 38, 3700.

22. Hassanabadi A, Anary-Abbasinejad M and Dehghan A, Synth Commun., 2009, 39. 132

23. Anary-Abbasinejad M, Anaraki-Ardakani H, Ezadi A and Hassanabadi A, J Chem Res., 2007, 605.

24. Anaraki-Ardakani H, Sadeghian S, Rastegari F, Hassanabadi A and AnaryAbbasinejad M, Synth Commun., 2008, 38, 1990.

25. Anary-Abbasinejad M, Anaraki-Ardakani H, Dehghan A, Hassanabadi A and Seyedmir M R, J Chem Res., 2007, 574.

26. Mosslemin M H, Anary-Abbasinejad M, Hassanabadi A and Bagheri M A, J Sulfur Chem., 2010, 31, 135.

27. Mosslemin M H, Tabatabaee M, Hassanabadi A and Lamei A, J Chem., 2011, 8(S1), S27-S32.

28. Anary-Abbasinejad M, Hassanabadi A and Mazraeh-Seffid M, J Chem Res., 2007, 708.

29. Hekmatshoar R, Souri S and Rahimifard M, Phosphorus, Sulfur and Silicon, 2004, 179(8), 1605-1609.

30. Eliel E L, Wilen S H and Mander L N, Stereochemistry of Organic Compounds, Wiley, New York, 1994, 569. 